\title{
Transition Process from Diffuser Stall to Stage Stall in a Centrifugal Compressor with a Vaned Diffuser
}

\author{
Nobumichi Fujisawa and Yutaka Ohta \\ Department of Applied Mechanics and Aerospace Engineering, Waseda University, 3-4-1 Okubo, Shinjuku-ku, Tokyo 169-8555, Japan \\ Correspondence should be addressed to Yutaka Ohta; yutaka@waseda.jp
}

Received 1 February 2017; Accepted 3 May 2017; Published 31 May 2017

Academic Editor: Gerard Bois

Copyright (c) 2017 Nobumichi Fujisawa and Yutaka Ohta. This is an open access article distributed under the Creative Commons Attribution License, which permits unrestricted use, distribution, and reproduction in any medium, provided the original work is properly cited.

\begin{abstract}
The transition process from a diffuser rotating stall to a stage stall in a centrifugal compressor with a vaned diffuser was investigated by experimental and numerical analyses. From the velocity measurements, it was found that the rotating stall existed on the shroud side of the diffuser passage in the off-design flow condition. The numerical results revealed the typical vortical structure of the diffuser stall. The diffuser stall cell was caused by the systematic vortical structure which consisted of the tornado-type vortex, the longitudinal vortex at the shroud/suction surface corner (i.e., leading edge vortex (LEV)), and the vortex in the throat area of the diffuser passages. Furthermore, the stage stall, which rotated within both the impeller and diffuser passages, occurred instead of the diffuser stall as the mass flow rate was decreased. According to the velocity measurements at the diffuser inlet, the diffuser stall which rotated on the shroud side was shifted to the hub side. Then, the diffuser stall moved into the impeller passages and formed the stage stall. Therefore, the stage stall was caused by the development of the diffuser stall, which transferred from the shroud side to the hub side in the vaneless space and expanded to the impeller passages.
\end{abstract}

\section{Introduction}

Centrifugal compressors equipped with vaned diffusers are widely used in industry because of their high pressure-rise characteristics. However, they are likely to result in unsteady phenomena, such as surges and rotating stalls, as compared with vaneless diffusers. The unstable operating range is enlarged by surges and rotating stalls that have the potential to cause serious accidents. Turbochargers are generally used for a wide operating range, including off-design conditions. However, centrifugal compressors are not subjected to similar operating conditions. Therefore, understanding the flow physics behind rotating stalls is important for improving high pressure compressor performance and for safe operation in off-design flow condition.

Many researchers have focused on rotating stalls in axial compressors [1-4]. In addition, several articles have also been devoted to the study of rotating stalls in centrifugal compressors [5-8]. In recent years, there has been a renewed interest in diffuser rotating stalls that occur in centrifugal compressors with vaned diffusers. For example, Spakovszky reported that four-cell backward travelling modal waves occur in the vaneless space prior to the surge [9]. Everitt et al. reported the generation mechanism of spike stall inception by numerical analysis [10]. The short wavelength stall inception in centrifugal compressors with vaned diffusers was caused by the separation on the shroud side of the diffuser leading edge and radial flow reversal throughout the vaneless space. As Bousquet et al. accurately pointed out, the growth of the amplitude of a modal wave rotating in the vaneless space led to occurrence of the diffuser rotating stall; this was evident from the numerical analysis [11]. The authors also have reported that the unsteady behavior of the diffuser stall was influenced by the unsteady vortices at the leading edge of the diffuser vane during the off-design operation $[12,13]$.

Furthermore, several researchers have reported that the rotating stall changed its scale and behavior in accordance with the decrement of mass flow rate in turbomachinery. In axial machines, Outa et al. showed that the flow blockages, which were generated and developed separately in the respective cascades of the rotor and stator, get coupled with each other and propagate as a stage stall cell with 


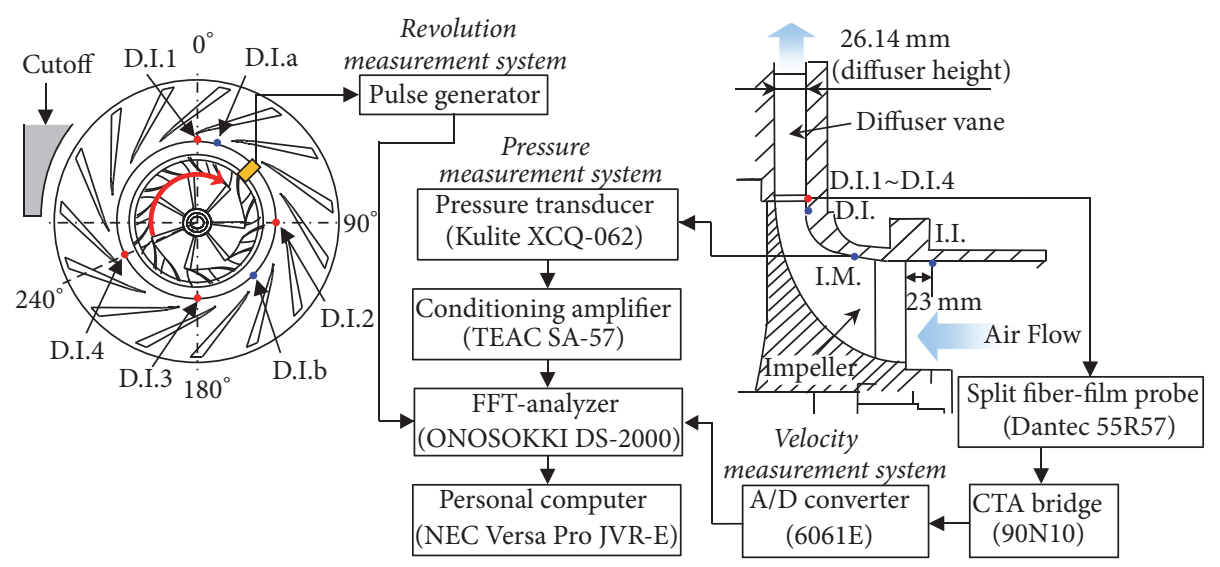

- Hot-wire anemometer

- Pressure transducer

FIGURE 1: Experimental apparatus and measuring system.

decreasing mass flow rate [14]. Yoshida et al. investigated the rotating stalls that occur in the impeller and diffuser passages [15]. The behavior of the rotating stall was found to be dependent on the impeller-diffuser radial gap. Mizuki and Oosawa experimentally reported unsteady flow patterns in a centrifugal compressor with a vaneless diffuser during rotating stall and surge [16]. The part-span stall at the leading edge of the impeller changed to a full-span stall, as the flow rate decreased. Moreover, the strong influence of the fullspan stall at the impeller inlet appeared during the surge. Zheng and Liu also examined the flow physics of rotating stalls and surge through their experiments [17]. The behavior of rotating stalls and surge was found to be dependent on the rotor speed and mass flow rate. However, very few researchers have reported on the transition process of the rotating stall via a detailed investigation of the internal flow field.

This study investigated the transition from the diffuser rotating stall to the stage stall in the vaned diffuser of a centrifugal compressor during the off-design operation. First, we focused on the generation mechanism of the diffuser stall by the both experimental and numerical analysis. The detached eddy simulation (DES) analysis was carried out to investigate the vortical structure of the diffuser stall. Secondly, we also investigated the transition characteristics of rotating stalls by the experiments.

\section{Experimental Apparatus and Procedure}

2.1. Experimental Apparatus. The compressor being tested had a centrifugal design based on that of a turbocharger used for marine diesel engines. The dimensions of the compressor are listed in Table 1 and the geometric configuration of the compressor and the main measurement system is illustrated in Figure 1. During the experiments, the rotational speed, $N$, of the compressor was set to $6000 \mathrm{~min}^{-1}$. The test impeller was an open-shroud type with seven main and splitter blades, and its inlet and outlet diameters were 248 and $328 \mathrm{~mm}$, respectively. The shroud clearance of the impeller
TABLE 1: Dimensions of tested compressor.

\begin{tabular}{lcc}
\hline \multicolumn{3}{c}{ Tested centrifugal compressor } \\
Rotational speed & $N$ & $6000 \mathrm{~min}^{-1}$ \\
Mass flow rate & $G$ & $1.64 \mathrm{~kg} / \mathrm{s}$ \\
Pressure ratio & $p_{t 5} / p_{t 1}$ & 1.1 \\
\hline \multicolumn{3}{c}{ Impeller } \\
Number of blades & $Z$ & 14 \\
(main + splitter) & & $(7+7)$ \\
Inlet diameter & $D_{1}$ & $248 \mathrm{~mm}$ \\
Outlet diameter & $D_{2}$ & $328 \mathrm{~mm}$ \\
Exit blade width & $B_{2}$ & $26.14 \mathrm{~mm}$ \\
\hline & & \\
Blade shape & Diffuser & Wedge \\
Number of vanes & $V$ & 15 \\
Leading edge Diameter & $D_{3}$ & $360 \mathrm{~mm}$ \\
Trailing edge Diameter & $D_{4}$ & $559 \mathrm{~mm}$ \\
Diffuser width & $B_{4}$ & $26.14 \mathrm{~mm}$ \\
\hline
\end{tabular}

was approximately $1.0 \%$ of the impeller inlet blade width, $B_{1}=105.6 \mathrm{~mm}$.

The vaned diffuser was employed in the experiments. The vaned diffuser had 15 wedge-type diffuser vanes located between two parallel diffuser walls of height, $B_{4}$, of $26.14 \mathrm{~mm}$. The distance between the impeller exit and diffuser leading edge, $L_{i d}$, was set to $16 \mathrm{~mm}$. The original wedge-type diffuser vane (ODV) was employed in the experiments. The vanes were attached to the shroud surface of the channel diffuser.

The volute was designed to give the circumferential uniform pressure at the design operation. Near to the stall point $(\phi=0.14)$, the flow is decelerated in the circumferential direction and the pressure rises around the volute. However, the fluctuation of circumferential pressure in vaneless space at the off-design point is $\pm 50 \mathrm{~Pa}$ at most, from the pressure measurements. Therefore, the unsteady behavior of diffuser stall was not highly affected by the volute design. 

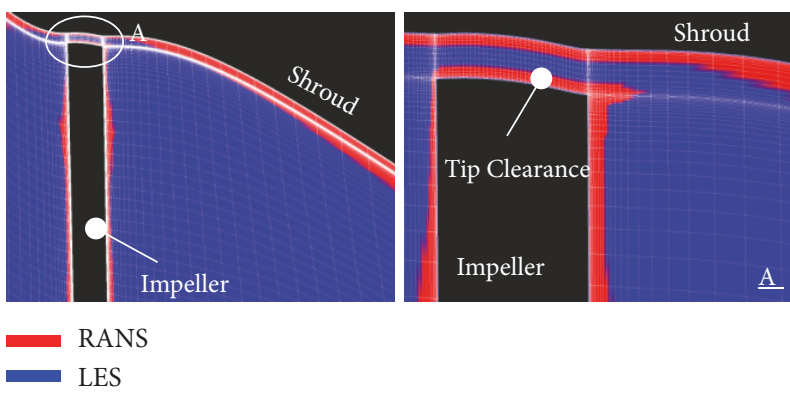

(a) Impeller passage
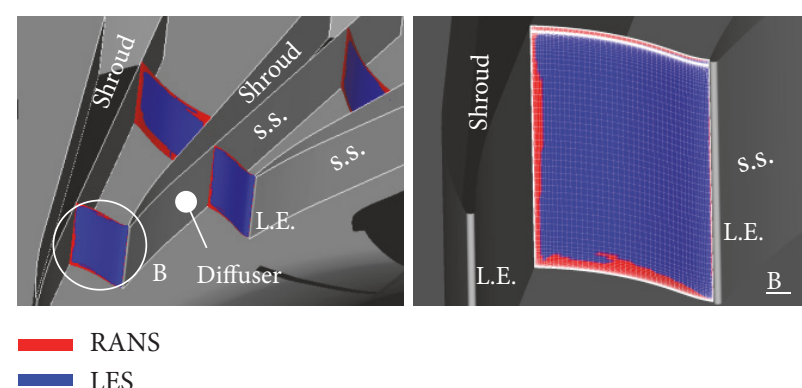

(b) Diffuser passage

FIGURE 2: RANS/LES region within impeller and diffuser passages.

2.2. Measuring Methods. The operation point of the compressor was set using a butterfly valve installed at the outlet duct. The mass flow rates were calculated using an orifice flow meter and a thermocouple installed at the outlet duct end. The pressure-rise characteristics were measured using a differential pressure transducer (Yamatake JTD920A) installed at the exit of the compressor scroll. The error of differential pressure probe was less than $\pm 0.1 \%$. The measuring bandwidth is from $2.0 \mathrm{kPa}$ to $14 \mathrm{MPa}$. The total pressure rise at the compressor exit was calculated by the pressure rise at the exit of the compressor scroll and the meridional velocity which was calculated by mass flow rate.

The pressure and velocity measuring systems for investigating unsteady phenomena are also illustrated in Figure 1. The pressure transducers (Kulite, XCQ-062-25A) with an error within $\pm 0.1 \%$ were mounted flush with the shroud surface of the compressor. The diameter of pressure probe head was $1.7 \mathrm{~mm}$. The pressure was measured at the following points along the impeller passage: impeller inlet (I.I.), impeller midsection (I.M.), and diffuser inlet (D.I.a and D.I.b). The diameter of above three points is $0.757 D_{2}$, $0.758 D_{2}$, and $1.024 D_{2}$, respectively. Furthermore, the spanwise distribution of the impeller-discharge flow was measured in the diffuser circumferential direction (D.I.1-D.I.4), using by a split-film probe (DANTEC, 55R57) with a constant-temperature anemometer (DANTEC, Streamline 90N10). The length of split-film probe was $8 \mathrm{~mm}$ and the film length was $1.25 \mathrm{~mm}$. The measurement location $D=339 \mathrm{~mm}$ was located between the impeller exit and the diffuser leading edge. The four measurement points are placed at $0 \mathrm{deg}$, $90 \mathrm{deg}, 180 \mathrm{deg}$, and $240 \mathrm{deg}$. The impeller-discharge flow measurement was traversed from the hub to the shroud side every $5 \%$ of the diffuser width (20 points). The unsteady pressure and velocity traces were measured at a sampling frequency of $25.6 \mathrm{kHz}$. The temporal resolution is about 20 samples per blade passing period.

\section{Computational Procedure}

3.1. Governing Equations. The present simulations were conducted using the in-house computational fluid dynamics (CFD) code, which had been validated for various turbomachinery flows. The code solved the governing equation of continuity, a three-dimensional compressible Navier-Stokes equation, an energy equation, and an equation for the state of an ideal gas. The convective flux was evaluated by the flux difference splitting (FDS) [18], which is extended to the third order using the monotonic upwind scheme for conservative laws (MUSCL) interpolation [19]. The viscous flux was determined as a second-order central difference using Gauss' theorem. The matrix free Gauss-Seidel (MFGS) implicit algorithm was employed for the time integration [20]. The DES approach, which is a hybrid scheme involving large eddy simulation (LES) and RANS [21], was employed in the turbulent modelling. The DES was based on the shear stress transport (SST) $k$ - $\omega$ turbulence model [22]. This model incorporates a dependency on the local turbulence length scale. The model constant $C_{\mathrm{DES}}$ was set to the value recommended by Strelets et al. Both Coriolis and centrifugal forces were considered to be inertial force terms in the relative coordinate system. The RANS and LES regions of both the impeller and diffuser passages are illustrated in Figure 2. This DES simulation code could transform the RANS-mode in regions near the wall into the LES-mode inside the fluid volume.

3.2. Computational Domains. The computational domains employed in the numerical simulations are illustrated in Figure 3. The grid system included all the flow passages (14 impeller and 15 diffuser passages). The computational domain was divided into three regions: the moving impeller, stationary diffuser, and the moving tip clearance regions. The volute region was not included in this simulation. For the whole domain including the tip clearance region, the mesh was generated with the multiblock structured grid using AutoGrid5 ver9.1 (NUMECA International). In the full annulus analysis, the impeller (including the clearance region) and diffuser system had 26.2 and 24.8 million cells, respectively. The computational grid incorporated seven main and splitter blades and 15 diffuser vanes and had 51.0 million cells. The cell width at the walls was $0.1 \mu \mathrm{m}$, which corresponded to a $y+$ parameter that was approximately equal to one along all solid surfaces. From the grid dependency test in partial annulus analysis, the grid density was sufficient in order to capture the unsteady behavior of vortices near the diffuser vane.

3.3. Boundary Conditions. At the inflow boundary, the total pressure and temperature were fixed. At the outflow boundary, a throttle resistance with a load coefficient was assumed 


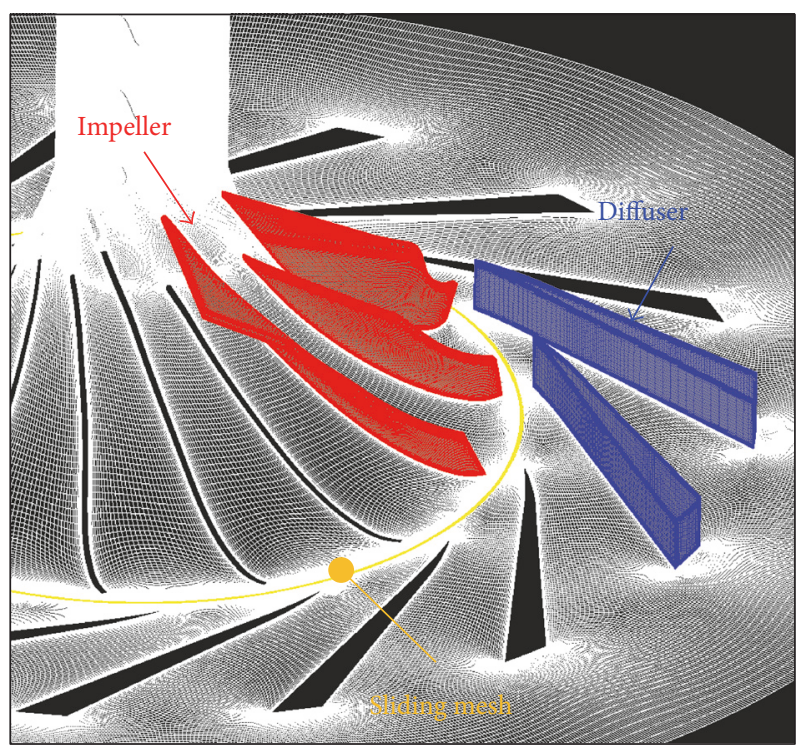

FIGURE 3: Overview of computational grid.

to exist between the boundary and the external atmosphere. The mass flow rate was not fixed at the outlet boundary because we assumed the throttle resistance with a load coefficient in order to simulate the velocity and pressure fluctuation caused by stall. We already observed the mass flow fluctuation at the exit of the compressor in both experiments and numerical simulations. Therefore, the static pressure at the outlet boundary was related to the mass flow rate through the boundary. Across the sliding boundary separating the moving impeller and stationary diffuser frames, the most recent data on one side was interpolated to obtain the data for the opposite side by using a sliding mesh for unsteady simulation. Nonslip and adiabatic conditions were adopted for the wall conditions.

\section{Results and Discussion}

4.1. Stall Characteristics of Tested Compressor. The experimental and numerical results of compressor performance are exhibited in Figure 4. The numerical total pressure-rise characteristics were obtained from DES unsteady analysis. The flow and total pressure-rise coefficients are defined as follows:

$$
\begin{gathered}
\phi=\frac{60 Q}{\pi^{2} D_{2}^{2} B_{2} N}, \\
\Psi_{t}=\frac{60^{2} \Delta p_{t}}{\rho \pi^{2} D_{2}^{2} N^{2} / 2} .
\end{gathered}
$$

The ODV experimental results were denoted by the black circles in the figure. The simulations were conducted at seven operating points from the design point $\left(\phi_{\mathrm{opt}}=0.24\right)$ to the deep stall point $(\phi=0.10)$. The time-averaged results of the unsteady DES analysis were in good agreement with the measured results obtained using the ODV, with the

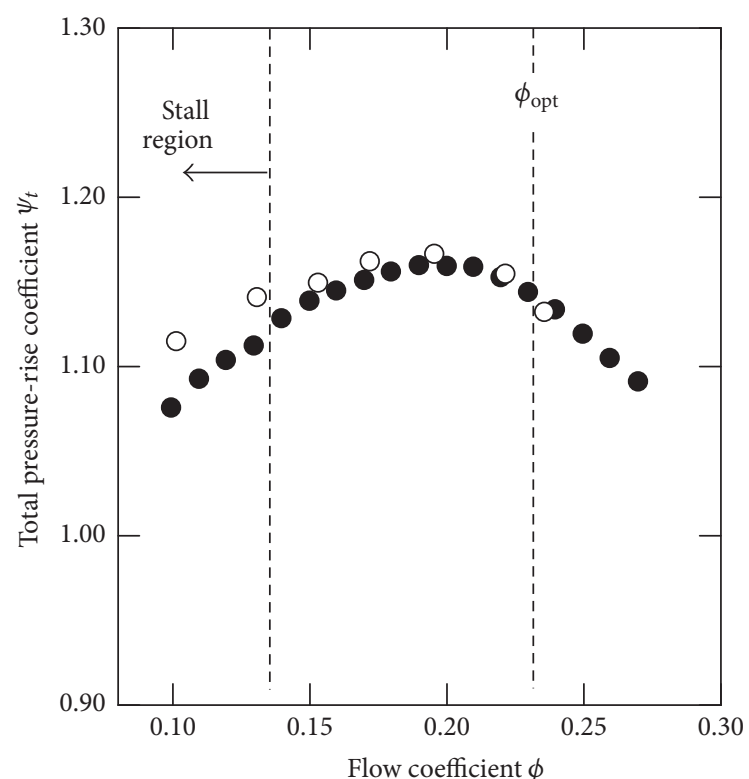

$\operatorname{ODV}(\mathrm{EXP})$

ODV (CFD)

FIGURE 4: Compressor performance.

exception of results at stall point $(\phi=0.14$ and 0.10$)$. One reason for this is that the additional loss from the volute was not concluded in this numerical simulation. Particularly at deep stall point $(\phi=0.10)$, the compressor performance data obtained numerically, using CFD, was higher in value than that obtained experimentally. The resulting question about the performance remarkably mismatch at $\phi=0.10$ is considered later in detail.

To investigate the unsteady characteristics of rotating stall, the impeller-discharge flow was measured with a splitfilm anemometer at $\phi=0.14$ and 0.10 . The spatial distribution of the FFT (Fast Fourier Transformation) results in the spanwise direction is shown in Figure 5. The vertical axis represents the intensity of radial velocity fluctuation. The measurement of flow coefficient, $\phi=0.14$, shows that the large intensity of velocity fluctuations occurred at $25 \mathrm{~Hz}$ near the shroud side. We have already reported that these unsteady phenomena at $25 \mathrm{~Hz}$, which were equivalent to $25 \%$ of the impeller rotational speed, were caused by the rotating stall within the diffuser passages [12]. Therefore, this disturbance, as illustrated in Figure 5(a), was considered to result from the diffuser stall fluctuations. When the mass flow decreased $(\phi=$ 0.10 ), the diffuser stall fluctuation was not found and a large intensity velocity fluctuation occurred at $22 \mathrm{~Hz}$ in Figure 5(b). From a previous study [23], we found that the large intensity fluctuations, called "stage stall," rotated within the impeller and diffuser passages. In comparison with the diffuser stall, the stage stall cell had a much larger intensity of velocity fluctuation over the entire span, especially near the hub side. In addition, from the pressure experiments, the number of diffuser and stage stall cell was found to be one. Thus, the rotating stall behavior of the tested compressor varied with the decreasing mass flow rate. 


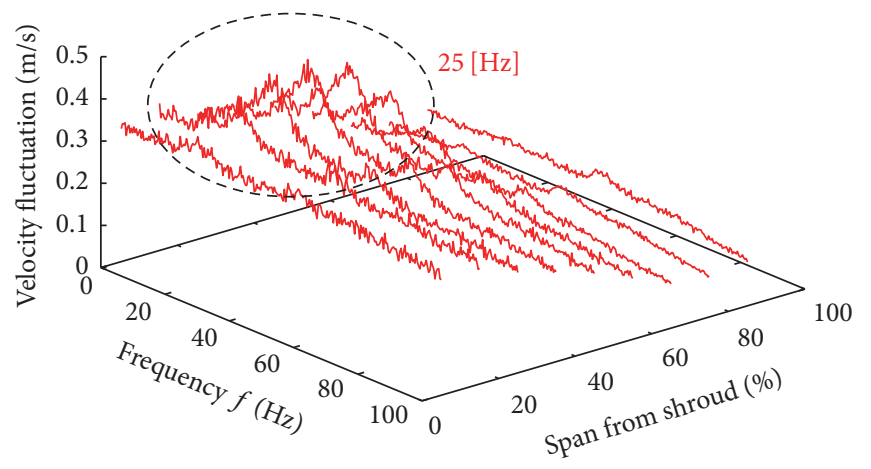

(a) $\phi=0.14$

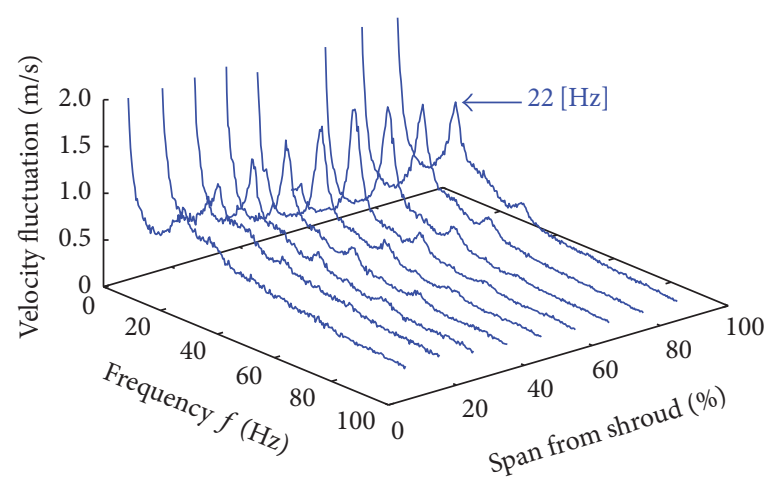

(b) $\phi=0.10$

FIGURE 5: Distribution of velocity fluctuation in spanwise direction (ODV).

4.2. Structure of Diffuser Stall Cell. First, the rotational structure of the diffuser stall cell at flow coefficient $\phi=0.14$ was investigated using numerical analysis. To investigate the unsteady characteristics of rotating stall, the casing wall static pressure fluctuation was measures at two positions (D.I.a and D.I.b). The experimental and numerical casing pressure traces are presented in Figure 6. The red lines represent the low-pass filtered traces and the low-pass filter frequencies were set to $30 \mathrm{~Hz}$. From the both experimental and numerical traces, the disturbance that was propagated in vaneless space can be observed. The rotational speed of this disturbance was approximately $25 \%$ of impeller speed. The unsteady phenomena at $25 \mathrm{~Hz}$, which were equivalent to $25 \%$ of impeller rotational speed, were caused by the diffuser rotating stall. In addition, the influence of impeller stall fluctuation could be excluded because the scale of disturbances caused by the impeller stall were much smaller than that of the diffuser stall at diffuser inlet from Figure 5. Therefore, the numerical results for diffuser stall were in good agreement with the results obtained by the experiments.

Furthermore, the instantaneous casing pressure fluctuations in the vaneless space at nondimensional times $t^{*}$ $=0.0-31.5$ are illustrated in Figure 7. The vertical axis is each diffuser vane, which was labelled with numbers from one to fifteen. The low casing static pressure region, which is represented by a black dashed circle, propagated to the next diffuser passage as time passed. The rotational speed of this region was approximately $25 \%$ of the impeller rotational speed. Thus, it may be concluded that this low static pressure region was caused by the diffuser rotating stall cell. Furthermore, the radial velocity fluctuation measured at the diffuser inlet is illustrated in Figure 8. The red and blue lines represent the diffuser passages numbers 1-2 and 78, respectively. The red dashed line, as illustrated in Figure 8, indicates the average of radial velocities calculated for all diffuser passages. As shown in this figure, the radial velocity of the diffuser passage numbers 7-8 was lower than the average radial velocity, because the diffuser rotating stall cell was approaching the diffuser passage numbers 7-8 from the nondimensional time, $t^{*} a=0.0$, as illustrated in Figure 7 . At the nondimensional time, $t^{*}{ }_{c}=4.5$, the radial velocity of

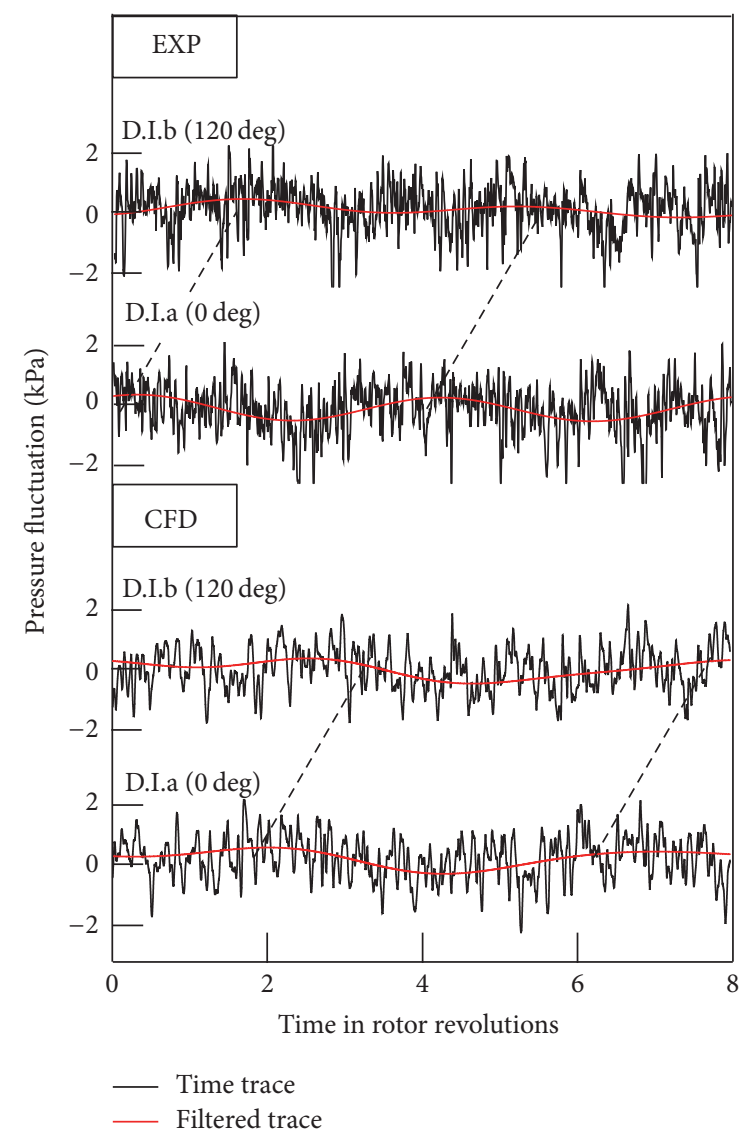

FIGURE 6: Casing wall pressure traces measured at diffuser inlet circumferential direction (D.I.a and D.I.b).

the diffuser passage numbers 7-8 was significantly decreased. Therefore, these results suggested that the flow within the diffuser passage was stalled by the blockage effect of the diffuser stall cell formation.

Then, the instantaneous vortical structure of the low static pressure region at the nondimensional time, $t^{*}{ }_{c}=$ 4.5 , is illustrated in Figure 9. The vortex structure within several stalled diffuser passages numbers 7-11, as illustrated 


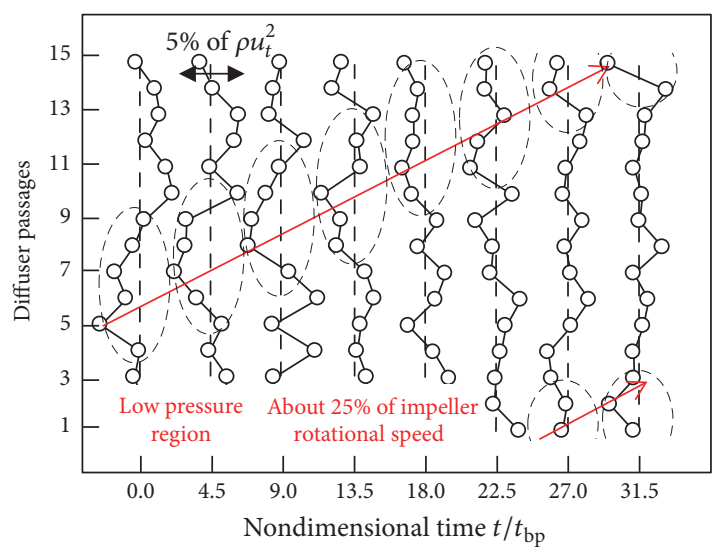

Figure 7: Casing static pressure fluctuations at diffuser inlet from nondimensional time $t^{*}=0.0$ to $t^{*}=31.5(\mathrm{CFD})$.

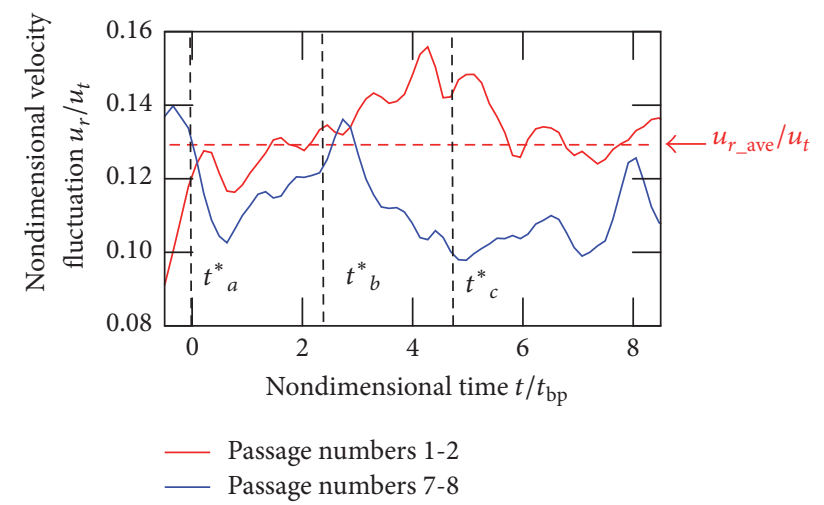

FIGURE 8: Radial velocity fluctuation measured at diffuser inlet (CFD).

in Figure 7, is visualized by Q-definition [24] and colored by nondimensional helicity. In the flow fields at the nondimensional time, $t^{*}{ }_{c}=4.5$, the tornado-type vortex connecting the shroud wall and diffuser suction surface was observed on the suction surface of diffuser vanes numbers 7 and 9. Longitudinal vortex was also developed on the suction surface of diffuser vanes numbers 8 and 10. This vortex is called the LEV. The LEV was developed and it formed a substantial blockage within the diffuser passages at offdesign points. Furthermore, the other vortical structure was found near the pressure surface of diffuser vanes numbers 8 and 10. This vortex formed a blockage in the throat area, which induced a strong reversal flow near the shroud side. Therefore, it was determined that the developed vortical structure was formed within the stall cell.

To understand the unsteady behavior of the diffuser stall cell, the instantaneous vortical structure within diffuser passages numbers 7-8 at nondimensional times $t^{*}{ }_{a}$, $t^{*}{ }_{b}$, and $t^{*}{ }_{c}$ was visualized. The vortex core colored by nondimensional helicity within diffuser passages numbers 78 is illustrated in Figure 10. First, the tornado-type vortex on the suction surface of the diffuser vane was generated at the nondimensional time $t^{*}{ }_{a}=0.0$. The tornado-type separation was caused by the positive incidence angle to the diffuser vane near the shroud side, which had resulted from the stall cell approaching diffuser passages numbers 7-8. Then, the tornado-type vortex was developed and the LEV was observed at the shroud/suction surface corner at the nondimensional time $t^{*}{ }_{b}=2.1$. The developed LEV was extended to the next diffuser vane (number 8 ) because of the high adverse pressure gradient within the diffuser passage. Additionally, the LEV leg was observed on the suction surface of the diffuser vane number 7. The LEV was caused by the secondary flow effect on the suction surface of the diffuser vane. The flow near the suction surface rolled up to the shroud side because of the vertical pressure gradient and formed the longitudinal vortex at the shroud/suction surface corner. At the nondimensional time, $t^{*}{ }_{c}=4.5$, the LEV interacted with the next diffuser leading edge and formed the throat area blockage, which induced the strong reversal flow near the shroud side. Accordingly, the separation vortex was considered as having been generated on the suction surface of diffuser vane number 8 with the passage of time, because the incidence angle to diffuser vane number 8 was highly positive. The newly formed tornado-type vortex and LEV were also observed near the leading edge of diffuser vane number 7 .

For an improved understanding of the generation mechanism of the vortices near the diffuser vane, the time-averaged distribution and isolines of the static pressure on the diffuser suction surface and casing wall are shown in Figure 11. The vectors on the suction surface and casing wall represent the pressure gradient vectors. Furthermore, the limiting streamlines on the diffuser suction surface are illustrated in Figure 12. Near the diffuser leading edge, the strength of vertical pressure gradient on the suction surface gradually increased from the hub to midspan because the tornado-type vortex resulted in the low-pressure region near the shroud side. From the limiting streamlines of the suction surface, the focus point of the tornado-type vortex leg was to be observed at the diffuser leading edge. In addition to this, the suction surface streamlines rolled up from the hub side to the shroud side because of the high vertical pressure gradient near the diffuser leading edge. As illustrated in Figure 11(b), the direction of circumferential pressure gradient vector on the shroud wall was strongly adverse near the suction surface of the diffuser leading edge, which was the origin of the tornadotype separation vortex. The pressure gradient vectors in the throat area were directed to the impeller exit and leading edge of the succeeding diffuser vane. This is because of the static pressure recovery within the diffuser passage.

To summarize, the structure of the diffuser stall is illustrated in Figure 13. Initially, the tornado-type vortex connecting the shroud wall and diffuser suction surface was generated on the suction surface of the diffuser vane. The LEV developed with the growth of the tornado-type vortex and it approached the succeeding diffuser vane because of the high adverse pressure gradient near the shroud side. Then, the developed LEV interacted with the succeeding diffuser leading edge and formed the throat area blockage with the passage of time. The blockage in the throat area induced the radial reversal flow of high magnitude near the shroud side, and the next separation vortex was formed because of the back flow. Finally, the throat area blockage 


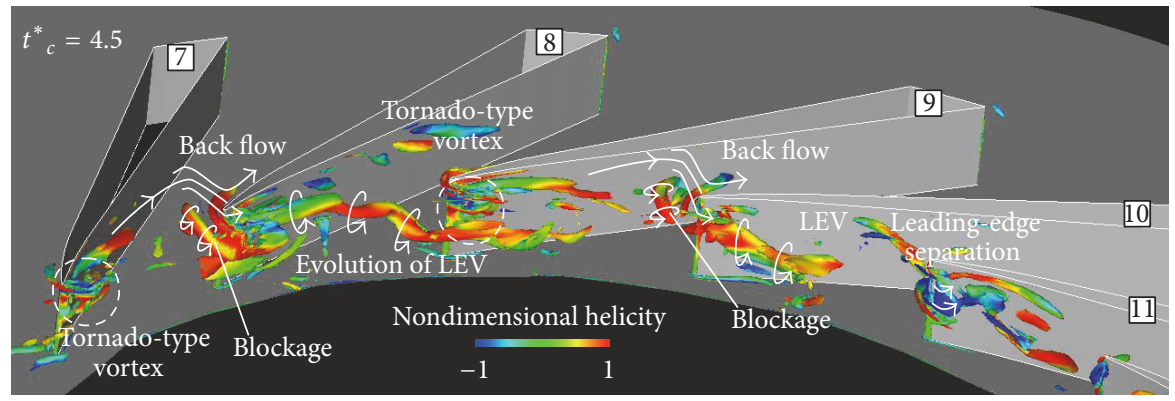

FIGURE 9: Instantaneous vortical structure of diffuser stall within diffuser passages number 7 to number 11.

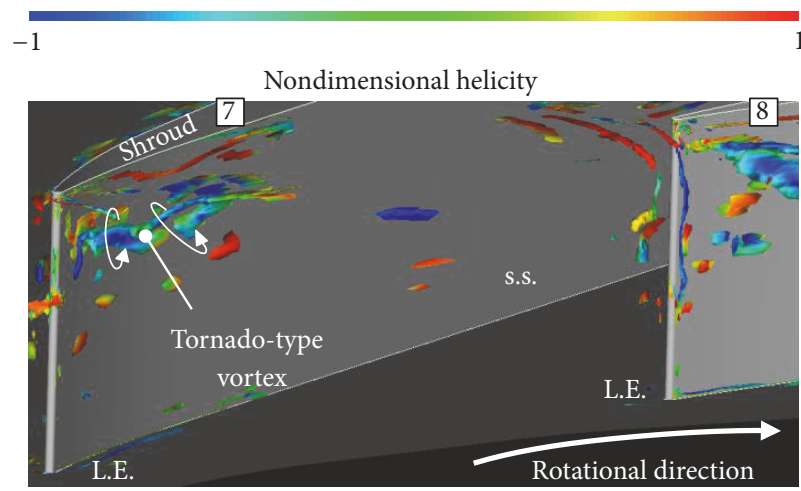

(a) $t_{a}^{*}=0.0$

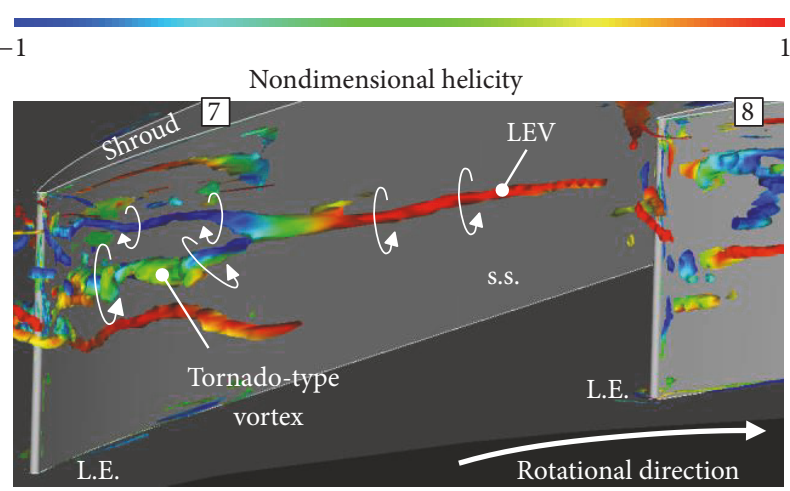

(b) $t^{*}{ }_{b}=2.1$

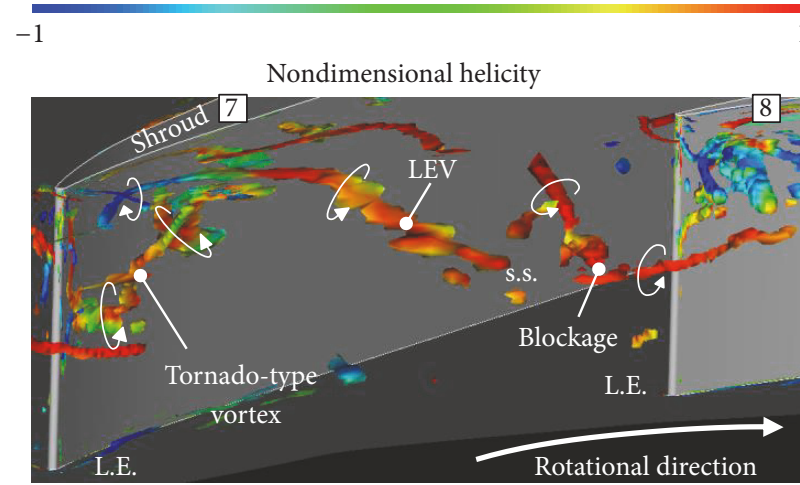

(c) $t^{*}{ }_{c}=4.5$

Figure 10: Instantaneous vortical structure within diffuser passage numbers 7-8 at nondimensional time $t^{*}{ }_{a}, t^{*}{ }_{b}$, and $t^{*}{ }_{c}$.

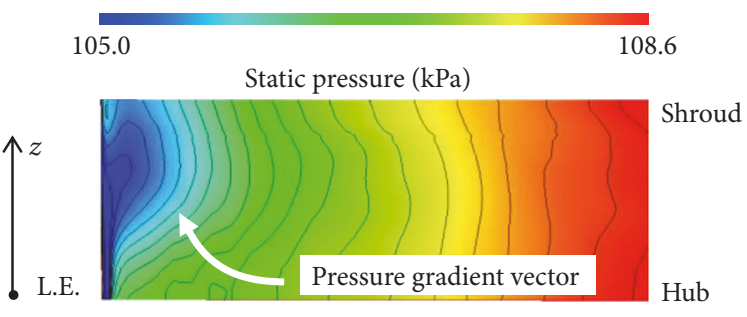

(a) Suction surface

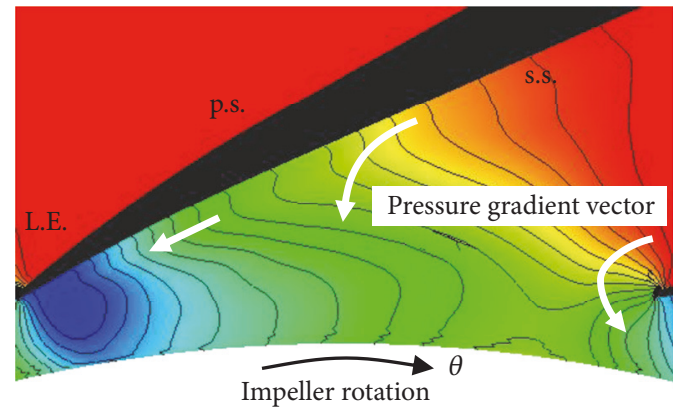

(b) Shroud surface

FIGURE 11: Distribution of static pressure on diffuser suction surface and casing wall. 


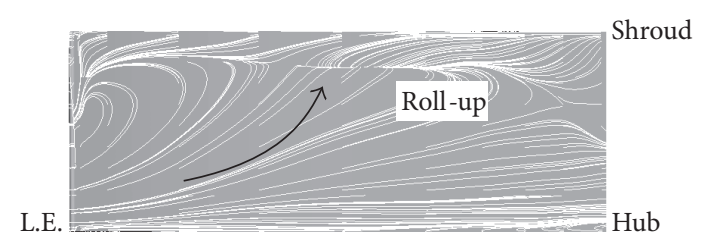

FIGURE 12: Limiting streamlines on diffuser suction surface.

resulted in the tornado-type vortex and LEV. The diffuser stall cell, which was formed by the systematic vortical structure and which consisted of the tornado-type vortex, LEV, and throat blockage, propagated to the succeeding diffuser vane. Therefore, the evolution of the tornado-type vortex and LEV was the cause of the diffuser rotating stall in the centrifugal compressor with a vaned diffuser.

The tested compressor is the low-pressure ratio centrifugal compressor; however the results of vortical structure of diffuser stall cell can be generalized not only low-pressure fluid machinery but also high pressure compressors. For example, Everitt et al. [10] reported the similar unsteady vortices at the diffuser leading edge in a high speed centrifugal compressor, as with the case of our paper. Furthermore, we confirmed that the LEV had the same form at high speed and the size of the LEV was increased at low mass flow late by CFD analysis, as we have mentioned in our previous paper [12]. Therefore, we may say that the knowledge obtained by this paper about the vortical structure of diffuser stall was also applied to the high pressure ration centrifugal compressor.

4.3. Transition to the Stage Stall. Next, the generation mechanism of the stage stall cell was investigated by experimental analysis at $\phi=0.10$. The velocity and pressure measurements were conducted to reveal the detailed flow fields, when the stage stall occurred. Figure 14 shows the measurement results of radial velocity and casing wall pressure traces $(30 \mathrm{~Hz}$ lowpass filter) at the diffuser inlet. The low-pass filter was conducted by the inverse Fourier transformation to the measured spectra which cut the high frequency range. The top left and right figures represent the radial velocity traces on the hub side and shroud side, respectively. The left two traces and the right one are measured simultaneously. These figures indicate that the radial reversed flow basically occurred on the shroud side and that the intensity of pressure fluctuation was small in the vaneless space (blue background color: condition (a)). However, the radial velocity was abruptly accelerated on the shroud side and decelerated on the hub side (red background color: condition (b)). Then, there was also a large intensity of pressure and velocity fluctuations (green background color: condition (c)). The cut-off frequency $(30 \mathrm{~Hz})$ is closer to the observed rotating stalls frequency $(25 \mathrm{~Hz}$ and $22 \mathrm{~Hz})$. However, the cut-off frequency was appropriate, because we focused on the whole intermittent process (conditions (a)-(c)) in this study. In addition, the spanwise radial velocity distributions of the impeller-discharge flow on the conditions (a) and (b) are measured at D.I.1-D.I.4 using by two splitfilm probes, as shown in Figure 15. One probe was set on the hub side in order to capture the stall conditions (a) to (c). Another velocity probe was set to measure the velocity distribution on each condition. On the flow condition (a), the flow on the shroud side was reversed at all measuring points. Furthermore, the reversed flow at D.I.1-D.I.4 moved from the shroud side to the hub side on condition (b). Thus, it was assumed that the flow condition in vanless space at $\phi=0.10$ was divided into three behaviors and switched unsteadily.

The power spectra of the velocity fluctuations on each condition in the vaneless space are shown in Figure 16. The velocity fluctuations (measured at $25 \mathrm{~Hz}$ ) caused by the diffuser stall were found near the shroud side on condition (a). Then, the diffuser rotating fluctuations transferred to the hub side on condition (b). Finally, the large intensity of the velocity fluctuation caused by the stage stall was found over the entire span, especially near the hub side. In addition, the low-pass filtered velocity traces were analyzed by wavelet transforms in order to estimate the unsteady behavior of the rotating stalls appearing in the compressor. The wavelet transform of a velocity signal, $u(t)$, is defined as follows:

$$
W(a, b)=\frac{1}{\sqrt{a}} \int \psi^{*}(T) u(t) d t,
$$

where $t$ is the time, $\psi^{*}(T)$ is a mother wavelet, $a$ is a scaling factor, $b$ is a time transformation factor, and $T=(t-b) / a$. In this work, the Gabor mother wavelet of

$$
\psi^{*}(T)=\frac{1}{\sqrt{2 \pi a}} e^{-T^{2} / 2 \sigma^{2}} e^{-i T}
$$

was applied for capturing rotating stall disturbances. Here, the constant parameter, $\sigma$, is defined as $\sigma=32$ in this work. Figure 17 shows the contour of the wavelet transform $W(a, b)$ for the low-pass filtered radial velocity traces on the hub side. The vertical axis indicated the frequency, $f$. When the radial velocity was decelerated, the diffuser stall fluctuation was appeared. Then, the unsteady disturbances at $25 \mathrm{~Hz}$ disappeared, and the stage stall fluctuation was found on condition (c). Finally, the stage stall fluctuation was not found on condition (a). Therefore, it was considered that the diffuser stall which rotated on the shroud side suddenly moved to hub side and evolved into stage stall.

Figure 18 shows the results of simultaneous measurement of radial velocity in vaneless space and casing wall pressure traces $(30 \mathrm{~Hz}$ low-ass filter) within impeller passages. The top figure is the radial velocity trace on the hub side. The bottom three figures represent the casing pressure traces in the meridional direction, I.I., I.M., and D.I.a. From the results at I.I. and I.M., the scale of pressure fluctuation in condition (b) was larger than condition (a), because the diffuser stall was considered to be expanded to impeller passages. In addition, the stage stall fluctuation was also found in the impeller passages. Figure 19 shows the power spectra of each flow condition measured on the impeller shroud wall in the meridional direction. The red, green, and blue lines indicate the pressure fluctuation level of I.I., I.M., and D.I.a. From these results, the diffuser stall cell was not found within the impeller passages on the flow condition (a). However, the pressure fluctuation of the diffuser stall occurred within the impeller passages on condition (b). Thus, the diffuser stall was considered to expand into the impeller passages 


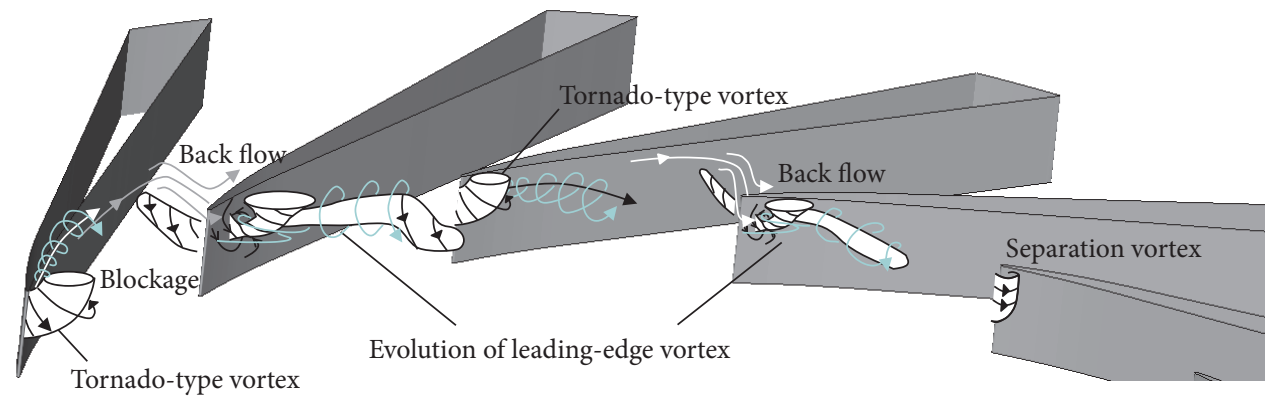

FIGURE 13: Illustration of rotating mechanism of diffuser stall cell.
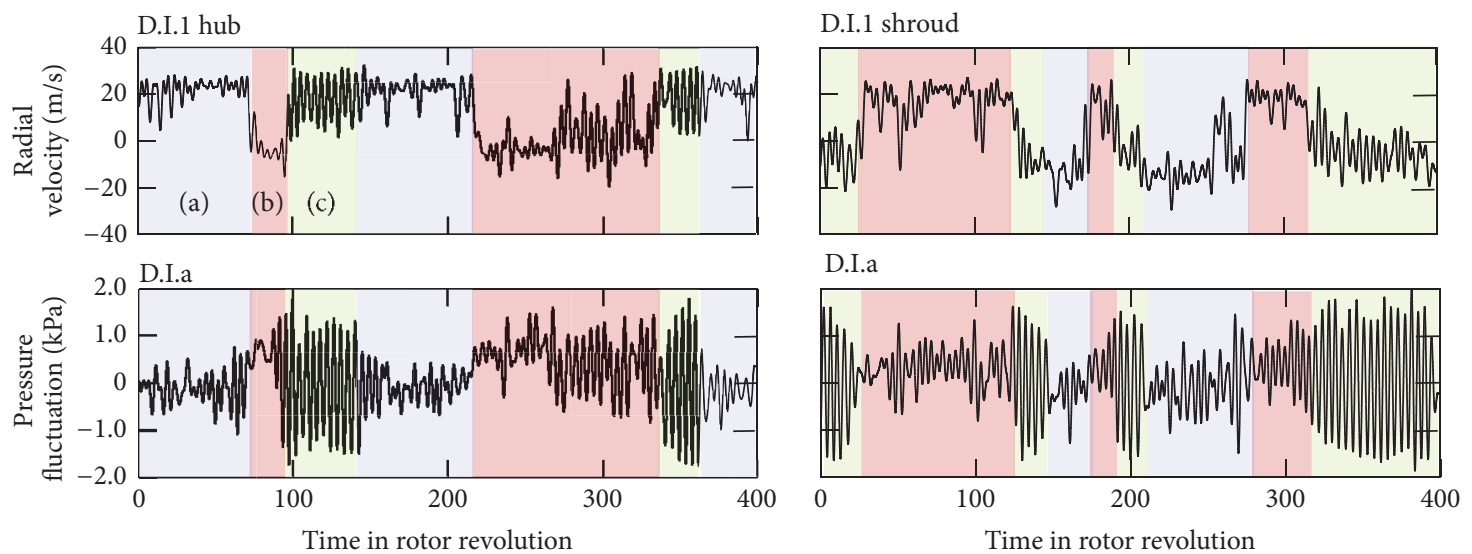

FIGURE 14: Radial velocity and pressure fluctuation traces at diffuser inlet ( $\phi=0.10,30 \mathrm{~Hz}$ low-pass filter).
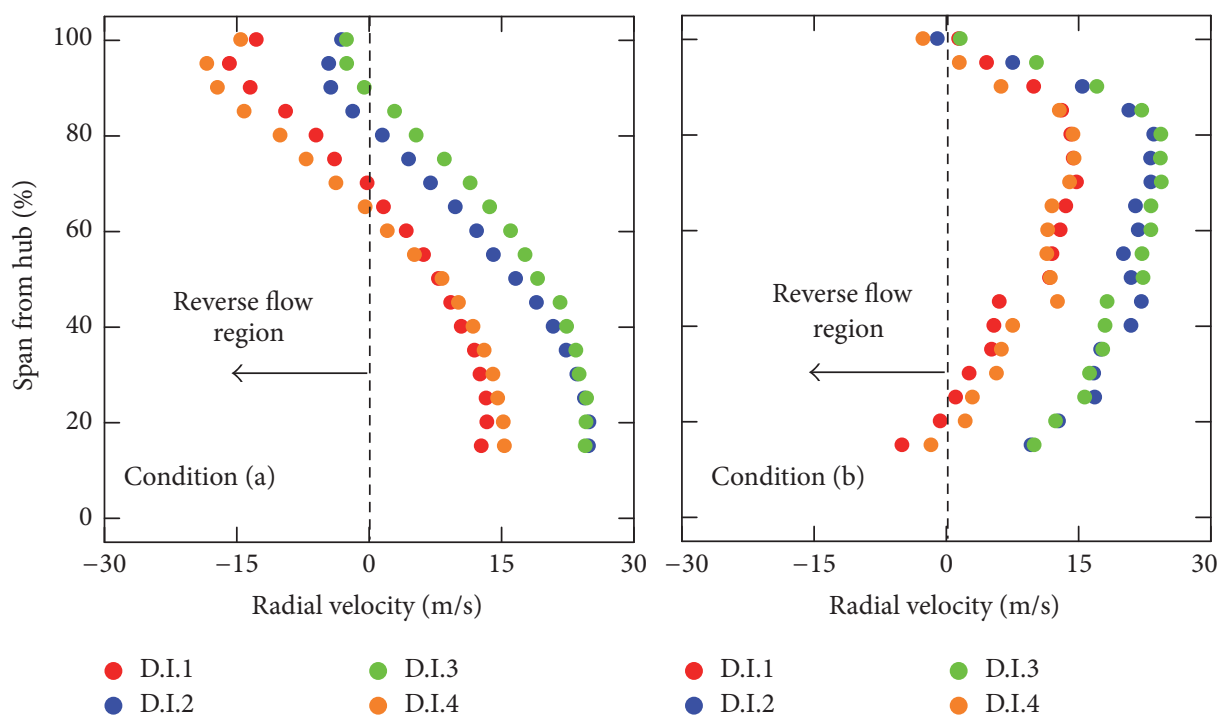

FIGURE 15: Spanwise radial velocity distributions of the impeller-discharge flow on conditions (a) and (b).

before the stage stall occurred. Finally, the stage stall cell was formed by the expansion of the diffuser stall on condition (c). Furthermore, the pressure fluctuations measured at $55 \mathrm{~Hz}$ were found from the power spectra of I.I. on conditions (a) and (b). Based on the previous report $[12,13]$, this $55 \mathrm{~Hz}$ pressure fluctuation was caused by the impeller rotating stall.
In the axial compressor, it was reported that the stall cells, which consisted of multiple vortices, merged into a single vortex cell. The single vortex cell blocked the flow in the rotor and stator passages as the mass flow rate decreased [14]. The suggested stall cell structure at the early stage in the axial compressors was similar to the diffuser stall cell observed 

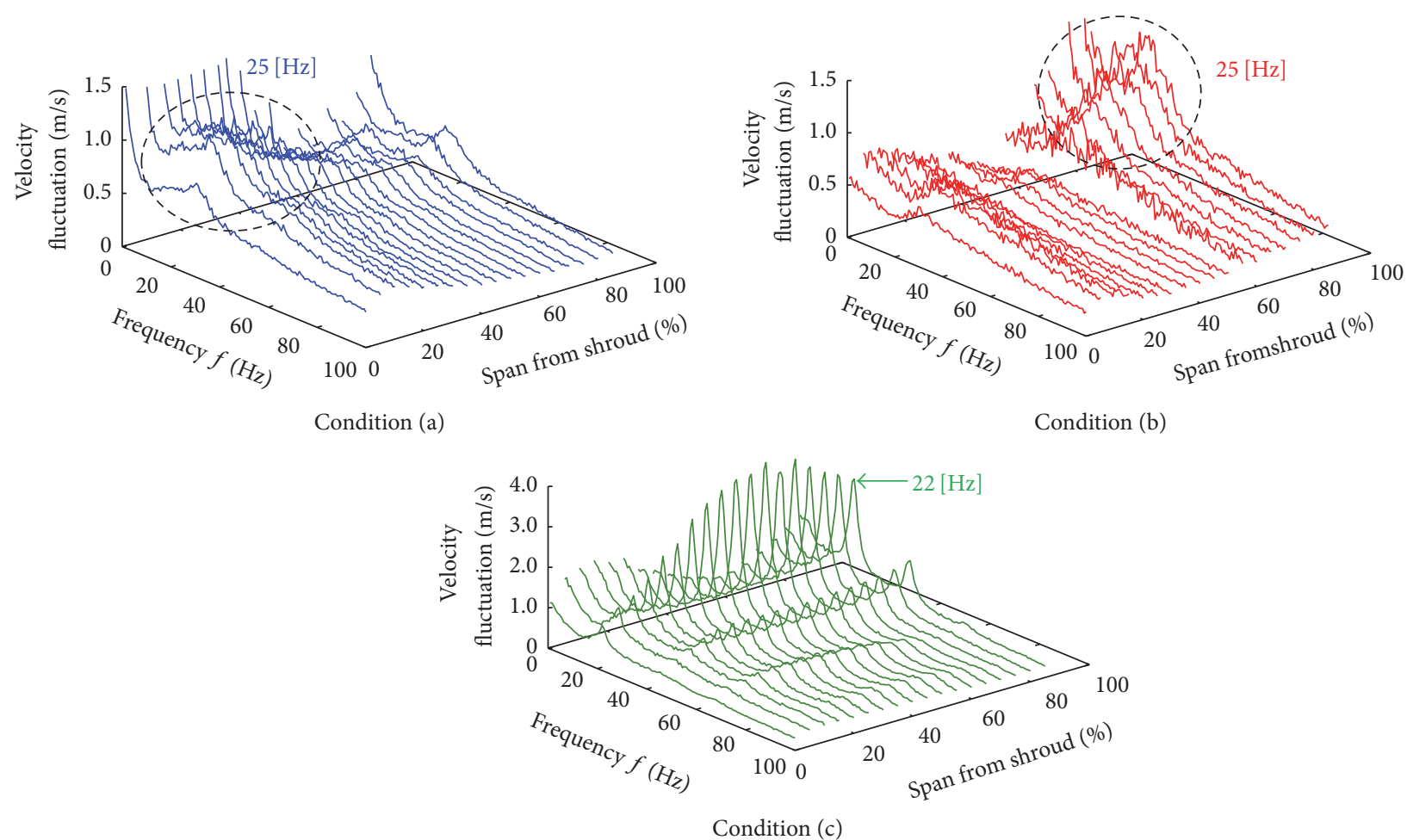

FIGURE 16: Distribution of velocity fluctuation in spanwise direction on three conditions (a) (c).

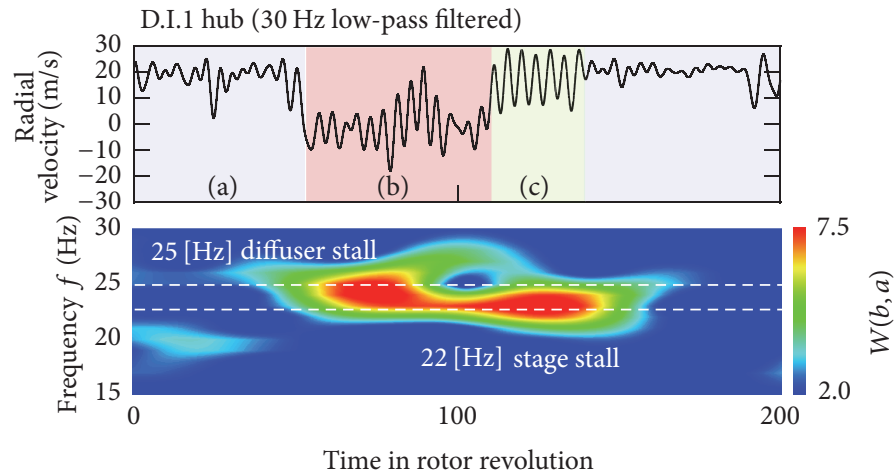

FIGURE 17: Contour map of the wavelet transform $W(a, b)$ for the low-pass filtered radial velocity traces on the hub side.

above. The CFD analysis was able to capture the impeller and diffuser stall cell; however the development from the diffuser stall to stage stall was not found at the flow coefficient $\phi=0.10$. Therefore, the performance mismatch between experimental and CFD results occurred at $\phi=0.10$ because the stage stall deteriorated the compressor performance. The detailed experimental and CFD analysis will be conducted in future studies to examine the relationship between the impeller and diffuser/stage stall cell.

In summary, the stage stall, which rotated within both impeller and diffuser passages, occurred instead of the diffuser stall as the mass flow rate was decreased $(\phi=0.10)$. The diffuser stall, which rotated on the shroud side, was suddenly shifted to the hub side. Then, the diffuser stall moved into the impeller passages and formed the stage stall. Therefore, the stage stall was caused by the development of the diffuser stall, which transferred from the shroud side to the hub side in the vaneless space and expanded to the impeller passages. In fact, the change in vertical structure from shifting the diffuser stall position was the key to understand the inception mechanism of stage stall. In future work, we will focus on the unsteady structure of diffuser stall before the occurrence of the stage stall by CFD analysis. In addition, we will reveal the clues of the stage stall getting back process to diffuser stall (conditions (c) to (a)).

\section{Conclusions}

The vortical structure of diffuser stall and the transition from diffuser stall to stage stall in a centrifugal compressor with 

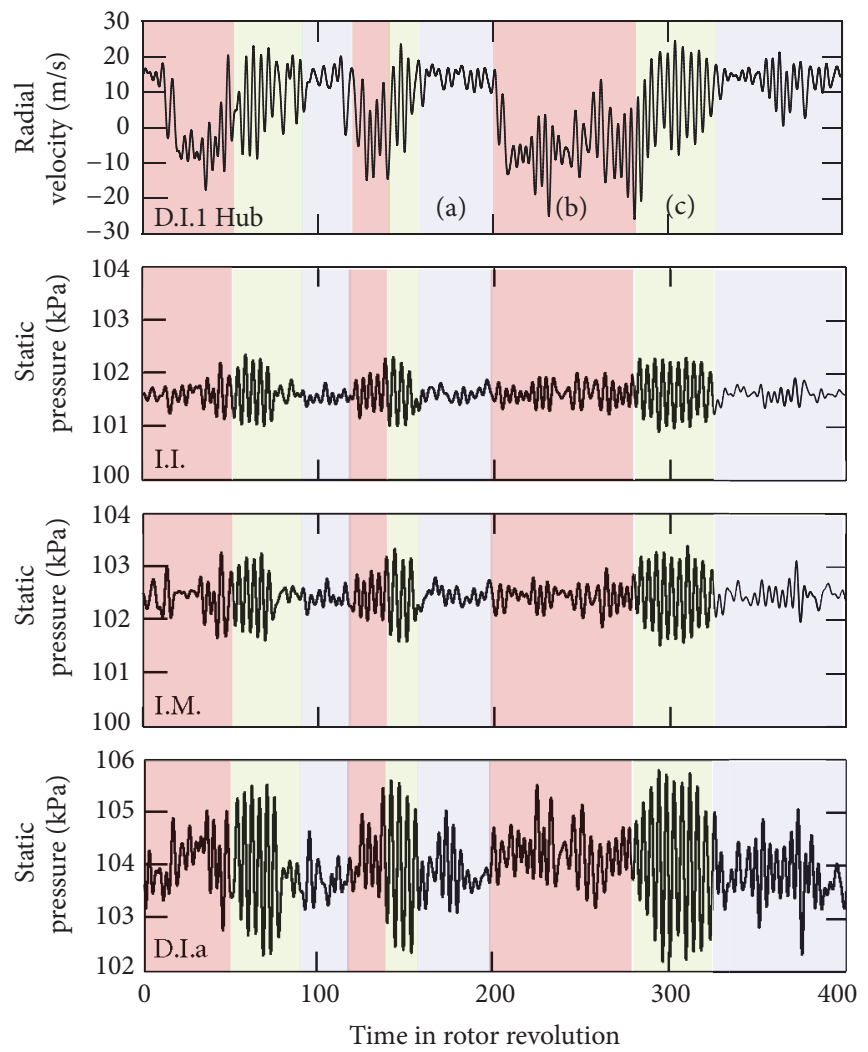

FIGURE 18: Radial velocity at diffuser inlet and static pressure traces at meridional direction $(\phi=0.10,30 \mathrm{~Hz}$ low-pass filter $)$.
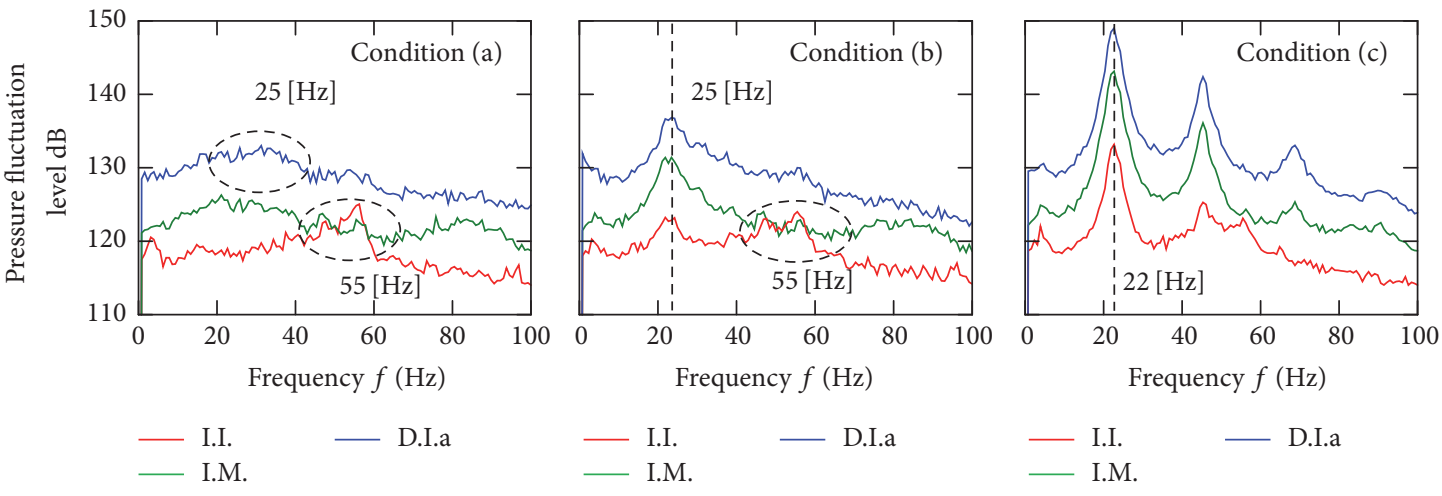

FIGURE 19: Power spectra of pressure fluctuations in impeller passage $(\phi=0.10)$.

a vaned diffuser were investigated by experimentation and through CFD analysis.

The results can be summarized as follows:

(i) In the tested compressor, the diffuser stall rotated at $25 \%$ of the impeller rotational speed during off-design flow operation. Both the experimental and numerical results revealed the rotation of the diffuser stall cell in the vaneless space on the shroud side of the flow passage. In addition, large fluctuations occurred at $22 \mathrm{~Hz}$, and were caused by stage stall when the mass flow rate decreased. The stage stall expanded over the entire span in the vaneless space. (ii) The vortical structure of the diffuser stall cell consisted of the tornado-type vortex, LEV, and throat blockage. The stall cell's typical vortical structure propagated to the succeeding diffuser passages.

(iii) The tornado-type separation was caused by the positive incidence angle to the diffuser vane near the shroud side. The LEV developed with the growth of the tornado-type vortex and extended to the succeeding diffuser vane. The developed LEV subsequently interacted with the succeeding diffuser leading edge and formed the throat area blockage. Finally, the tornado-type vortex and LEV were developed by the throat area blockage. The diffuser rotating stall was 
caused by the evolution of the tornado-type vortex and LEV.

(iv) The diffuser stall which rotated on the shroud side was suddenly shifted to the hub side as the mass flow rate decreased. The diffuser stall then moved into the impeller passages and formed into the stage stall. The stage stall was caused by the development of the diffuser stall, which transferred from the shroud side to the hub side in the vaneless space and expanded to the impeller passages.

\section{Nomenclature}

$B$ : Diffuser passage height $(\mathrm{m})$

D: Diameter $(\mathrm{m})$

$G$ : Mass flow rate $(\mathrm{kg} / \mathrm{s})$

$L_{i d}$ : Distance between impeller exit and diffuser leading edge $(\mathrm{m})$

$N$ : Rotational speed $\left(\mathrm{min}^{-1}\right)$

$Q:$ Volume flow rate $\left(\mathrm{m}^{3} / \mathrm{s}\right)$

$W$ : Wavelet coefficient

$V:$ Number of diffuser vanes

$Z$ : Number of impeller blades

$f:$ Frequency $(\mathrm{Hz})$

$t$ : Time (s)

$t_{\mathrm{bp}}$ : Blade passing time (s)

$t^{*}:$ Nondimensional time $\left(=t / t_{\mathrm{bp}}\right)$

$p: \quad$ Static pressure $(\mathrm{Pa})$

$p_{t}$ : Total pressure $(\mathrm{Pa})$

$u$ : Velocity $(\mathrm{m} / \mathrm{s})$

$u_{r}$ : Radial velocity $(\mathrm{m} / \mathrm{s})$

$u_{t}$ : Circumferential velocity at impeller exit $(\mathrm{m} / \mathrm{s})$.

Greek Letters

$\rho: \quad$ Air density $\left(\mathrm{kg} / \mathrm{m}^{3}\right)$

$\phi:$ Flow coefficient

$\psi_{t}$ : Total pressure-rise coefficient

$\psi^{*}$ : Mother wavelet function.

\section{Subscripts}

1: Impeller inlet

2: Impeller outlet

3: Diffuser leading edge

4: Diffuser trailing edge.

\section{Abbreviations}

D.E.: Diffuser exit

D.I.: Diffuser inlet

I.I.: Impeller inlet

I.M.: Impeller midsection

LEV: Leading edge vortex

ODV: Original wedge-type diffuser vane.

\section{Conflicts of Interest}

The authors declare that they have no conflicts of interest.

\section{Acknowledgments}

This work was supported by Grant-in-Aid for Research Activity Start-Up no. 16H07293 from Japan Society for the Promotion of Science.

\section{References}

[1] F. K. Moore and E. M. Greitzer, "A theory of post-stall transient in axial compressor systems: part 1 development of equations," ASME Journal of Engineering for Gas Turbines Power, vol. 108, pp. 69-76, 1986.

[2] E. M. Greitzer and F. K. Moore, "A theory of post-stall transient in axial compressor systems: part 2 application," ASME Journal of Engineering for Gas Turbines and Power, vol. 108, no. 2, pp. 231-239, 1986.

[3] I. J. Day, "Stall inception in axial flow compressors," ASME Journal of Turbomachinery, vol. 115, pp. 1-9, 1993.

[4] M. Inoue, M. Kuroumaru, T. Tanino, and M. Furukawa, "Propagation of multiple short-length-scale stall cells in an axial compressor rotor," Journal of Turbomachinery, vol. 122, no. 1, pp. 45-54, 2000.

[5] U. Haupt, M. Rautenberg, and A. N. Abdel-Hamid, "Blade excitation by broad-band pressure fluctuations in a centrifugal compressor," ASME Journal of Turbomachinery, vol. 110, no. 1, pp. 129-137, 1988.

[6] U. Haupt, U. Seidel, A. N. Abdel-Hamid, and M. Rautenberg, "Unsteady flow in a centrifugal compressor with different types of vaned diffusers," ASME Journal of Turbomachinery, vol. 110, no. 3, pp. 293-302, 1988.

[7] I. Tomita, S. Ibaraki, M. Furukawa, and K. Yamada, "The effect of tip leakage vortex for operating range enhancement of centrifugal compressor," Journal of Turbomachinery, vol. 135, no. 3, Article ID 051020, 2013.

[8] Y. Fukuda, Y. Takeyama, and Y. Ohta, "Characteristics of rotating instability in a centrifugal blower with shrouded impeller," Transactions of the JSME, vol. 80, no. 809, pp. 1-11, 2014 (Japanese).

[9] Z. S. Spakovszky, "Backward traveling rotating stall waves in centrifugal compressors," Journal of Turbomachinery, vol. 126, no. 1, pp. 1-12, 2004

[10] J. N. Everitt and Z. S. Spakovszky, "An Investigation of Stall Inception in Centrifugal Compressor Vaned Diffuser," Journal of Turbomachinery, vol. 135, no. 1, Article ID 011025, 2012.

[11] Y. Bousquet, N. Binder, G. Dufour, X. Carbonneau, M. Roumeas, and I. Trebinjac, "Numerical simulation of stall inception mechanisms in a centrifugal compressor with vaned diffuser," Journal of Turbomachinery, vol. 138, no. 12, Article ID 121005, 2016.

[12] N. Fujisawa, S. Hara, Y. Ohta, and T. Goto, "Unsteady behavior of leading edge vortex and diffuser stall inception in a centrifugal compressor with vaned diffuser," in Proceedings of the ASME FEDSM 2014, 2014.

[13] N. Fujisawa, S. Ikezu, and Y. Ohta, "Structure of Diffuser Stall and Unsteady Vortices in a Centrifugal Compressor," in Proceedings of the ASME Turbo Expo 2016, 2016.

[14] E. Outa, Y. Ohta, D. Kato, and K. Chiba, "Two-dimensional study on evolution of deep rotating stall under uniform inlet conditions in an axial compressor cascades," in Proceedings of the 14th International Society for Air Breathing Engines, pp. 1-11, 1999. 
[15] Y. Yoshida, H. Tsurusaki, Y. Murakami, and Y. Tsujimoto, "otating stalls in centrifugal impeller/vaned diffuser systems (1st Report)," Transactions of the JSME, vol. 56, no. 530, pp. 29912998, 1990 (Japanese).

[16] S. Mizuki and Y. Oosawa, "Unsteady flow within centrifugal compressor channels under rotating stall and surge," Journal of Turbomachinery, vol. 114, no. 2, pp. 312-320, 1992.

[17] X. Zheng and A. Liu, "Phenomenon and mechanism of tworegime-surge in a centrifugal compressor," Journal of Turbomachinery, vol. 137, no. 8, Article ID 081007, 2015.

[18] J. L. Steger and R. F. Warming, "Flux vector splitting of the inviscid gasdynamic equations with application to finitedifference methods," Journal of Computational Physics, vol. 40, no. 2, pp. 263-293, 1981.

[19] B. van Leer, "Towards the ultimate conservative difference scheme. V. A second-order sequel to Godunov's method," Journal of Computational Physics, vol. 32, no. 1, pp. 101-136, 1979.

[20] E. Shima, "A simple implicit scheme for structured/unstructured cfd," in Proceedings of 29th Fluid Dynamic Conference, pp. 325-328, 1997.

[21] P. R. Spalart, M.-H. Jou, M. Strelets, and S. R. Allmaras, "Comments on the feasibility of les for wings and on the hybrid rans/les approach, advances in DNS/LES," in Proceedings of the First AFOSR International Conference on DNS/LES, 1997.

[22] M. Strelets, "Detached Eddy simulation of massively separated flows," AIAA Paper, Article ID 2001-0879, 2001.

[23] S. Ikezu, N. Fujisawa, and Y. Ohta, "Characteristics of a Centrifugal Compressor with Vaned Diffuser," in Proceedings of the 6th Asian Joint Workshop on Thermophysics and Fluid Science, 2016.

[24] J. Jeong and F. Hussain, "On the identification of a vortex," Journal of Fluid Mechanics, vol. 285, pp. 69-94, 1995. 


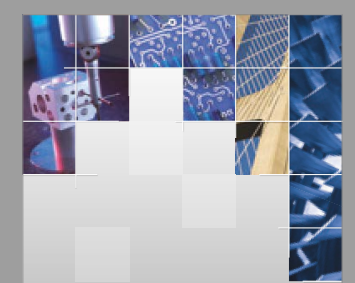

\section{Enfincering}
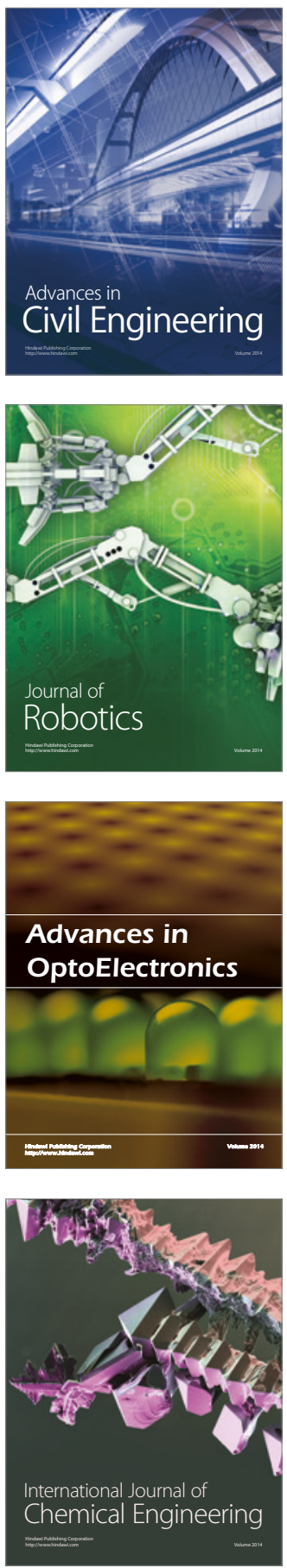

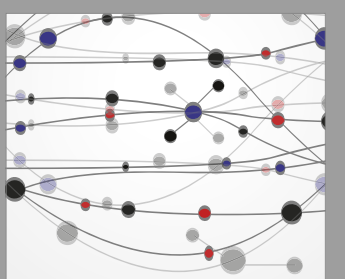

The Scientific World Journal

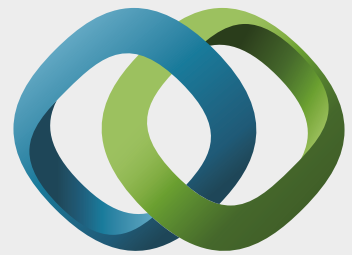

\section{Hindawi}

Submit your manuscripts at

https://www.hindawi.com
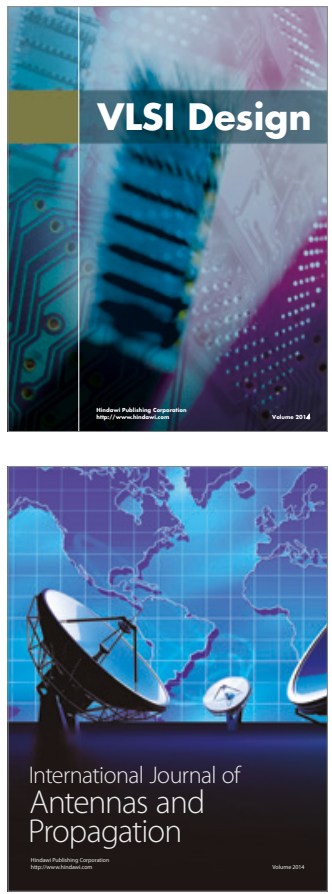

\section{Rotating}

Machinery
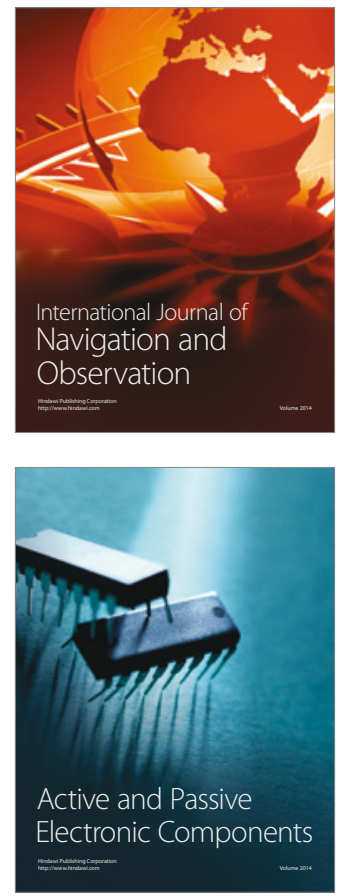
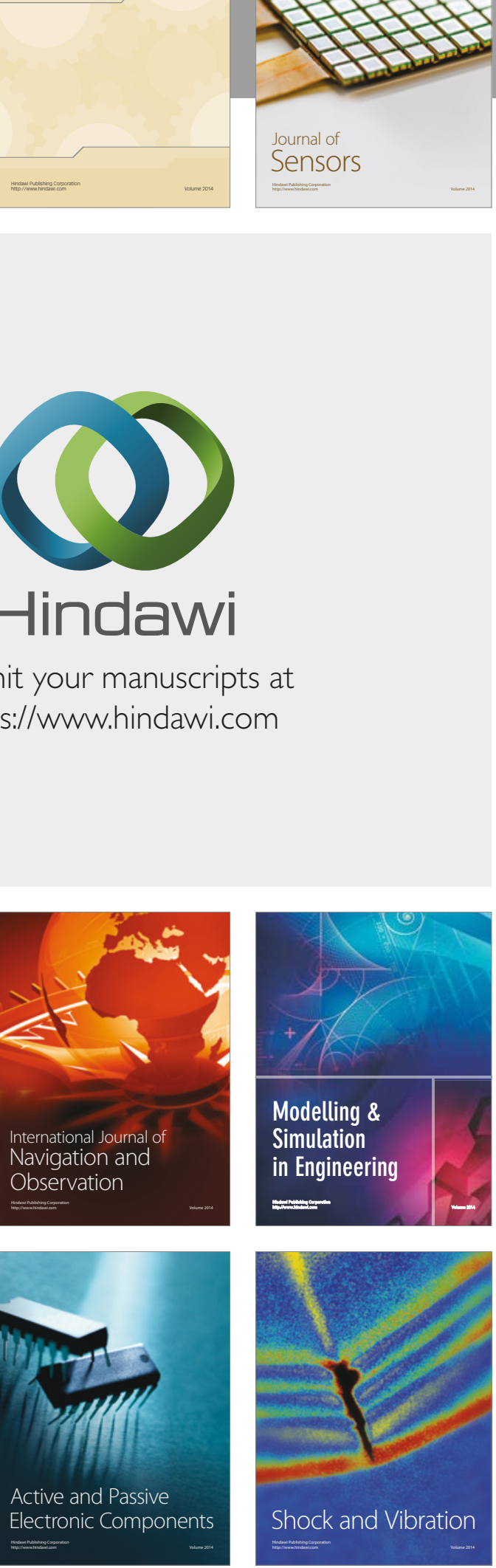
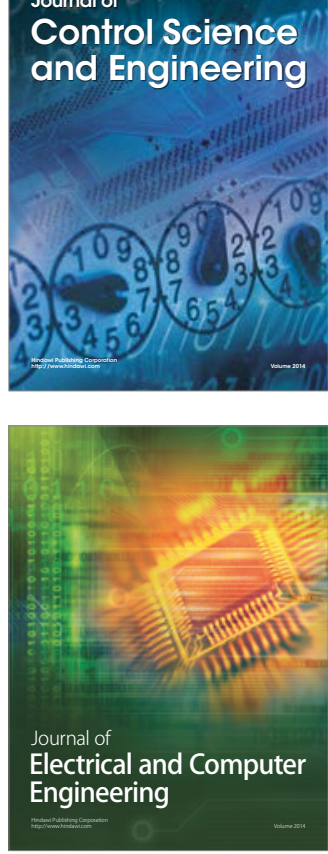

Distributed

Journal of

Control Science

and Engineering
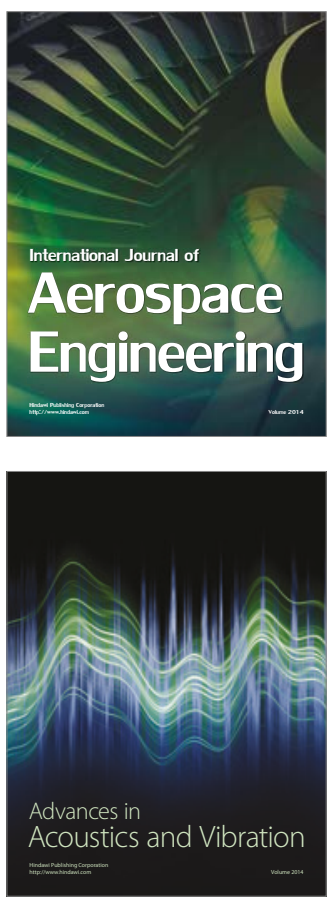

Sensor Networks 